\title{
Global Empathic Consciousness Development: Mass Communication Hope?
}

\section{Ronald D. Gordon}

Department of Communication, Humanities Division, College of Arts \& Sciences, The University of Hawaii - Hilo, U.S.A.

\begin{abstract}
Jeremy Rifkin's recent perspective on global empathic consciousness development is summarized, then related to current global media practices. It is argued that media preoccupation with violence, commodification, and "entertainment" as its supra-ideologies does not serve well the further development of empathic regard for the peoples of the Earth and for our biosphere. The central nervous system extensions (a la McLuhan) of the global Western media empire have been drawn excessively from the lower and more primitive brain regions, the "reptilian" brain and the "fight-and-flight" reactivity of the limbic system, and it is time to up-level future extensions out into the world consciousness system. The notion of "mass communication hope" is raised, and eight recommendations to concerned mass communication scholars are made in response to the question "What can we do?": (1) we can promote dialogue on ethical / neuroethical issues; (2) we can further question underlying media assumptions; (3) we can accelerate the call for media reform; (4) we can catalogue, comment upon, and publicize existing prosocial media themes, scenes, and images; (5) we can pursue further prosocial media research; (6) we can link to positive psychology research efforts; (7) we can synthesize diverse strands of prosocial research across disciplinary lines; (8) we can stimulate and facilitate ongoing dialogue on what is needed. The hope and aim is to help meet human and planetary needs for wholeness, empathy, depth of awareness, and harmony of all being.
\end{abstract}

\section{Introduction}

Simonson [1] included John Dewey among the early $20^{\text {th }}$ century thinkers "who fell prey to a dream that I call communication hope, a dream that continues to resonate today. It is the hope that communication, especially mass communication, might bring about a new and perhaps unprecedented unity among people." Dewey envisioned the "Great Community." Many today share a similar dream, not only for a single country but for the world community. Yet Simonson warns us that "communication hope" is blind to the economic, political, and social realities upon which the commercial mass media are "parasitic," and that one should not have one's hopes naively high. As true as this may be, John Lennon's lyric echoes in the mind: "You may say I'm a dreamer, but I'm not the only one. I hope someday you'll join us, and the world will live as one."

In this commentary paper we will briefly summarize Rifkin's [2] recent call for a hastening of global empathic consciousness development on the planet Earth, then link this call for empathic consciousness development to current mass media practices and potentials (which Rifkin does not address), and, finally, suggest implications for mass communication scholars, researchers, and practitioners.

\section{Global Empathic Consciousness Development}

In a nearly seven hundred page tour d' force titled The Empathic Civilization: The Race to Global Consciousness in a World in Crisis, Jeremy Rifkin [2] attempts to re-view human history through the lens of empathic consciousness development, a human journey across 175,000 years toward an increasingly greater ability to feel and imagine our way into the experiences, minds, and feelings of our fellow human beings. He argues that historians have mostly ignored human empathic consciousness development in their own renditions of our human story, and instead have chronicled the exercise and abuses of power, the inevitability and consequences of economic greed, the constantly recurring conflicts and wars, and the hero and villain narratives, all the while granting scant attention to the evolution and extension of human empathic consciousness across time. Rifkin asserts in his opening chapter that "Our collective memory is measured in terms of crises and calamities, harrowing injustices, and terrifying episodes of brutality inflicted on each other and our fellow creatures. But if these were the defining elements of human experience, we would have perished as a species long ago."

Meanwhile and more quietly over the past epochs of history, in Rifkin's depiction, humankind's empathic consciousness has slowly developed. New technological eras and their accompanying communication revolutions in particular have reconfigured not only societies but human consciousness, changing the way that the human brain engages with other human beings. Rifkin's sweeping treatment [2] of the development and recognition of empathic consciousness includes surveying a wide range of topics including biological evolution, the development of language, key historical periods (e.g., the European Romantic period and the Renaissance), the creation of democratic values and structures, religious diversity, the concept of companionate marriage and advances in parenting, evolving schools of philosophical thought, urban living and cosmopolitanism, innovations in media technologies, primate research, recent child development research, the cultural influence humanistic psychology, the ease of geographical travel, and so on. Rifkin observes (Ch. 2) that Charles Darwin, later in his life, came to realize more clearly that

*Corresponding Author: Dr. Ronald D. Gordon, Department of Communication, The University of Hawaii - Hilo, 200 W. Kawili Street, Hilo, HI 96720, U.S.A., E-mail: rgordon@hawaii.edu

Citation: Gordon RD (2016) Global Empathic Consciousness Development: Mass Communication Hope? Int J Journalism Mass Comm 3: 116. doi: http:// dx.doi.org/10.15344/2349-2635/2016/116

Copyright: ( $) 2016$ Gordon. This is an open-access article distributed under the terms of the Creative Commons Attribution License, which permits unrestricted use, distribution, and reproduction in any medium, provided the original author and source are credited. 

Citation: Gordon RD (2016) Global Empathic Consciousness Development: Mass Communication Hope? Int Journalism Mass Comm 3: 116. doi: http://dx.doi.
org/10.15344/2349-2635/2016/116

Page 2 of 9 \begin{tabular}{ll}
\hline human survival entails every bit as much cooperation as competition, & narrowing rather than an expanding of human consciousness." He \\
and that Darwin foresaw a time when humanity will be even & suggests that our future as a species may well rest on whether we can
\end{tabular} further expanded in empathic expression. Rifkin asserts that "it is accelerate more widespread movement toward total global empathy.

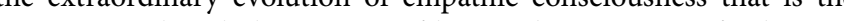
quintessential underlying story of human history, even if it has
been given the serious attention it deserves by our historian"

Rifkin proffers the increasingly scientifically-supported view that the empathic predisposition is biologically built-into we humans, and facilitates our bonding with others, and potentially with our
extended human family. He cites (Ch. 4), for instance, research that extended human family. He cites (Ch. 4), for instance, research that
demonstrates that infants as young as six months of age prefer to see demonstrates that infants as young as six months of age prefer to see
strangers helped rather than hindered in moving toward their chose goal -- they value seeing someone serve in the Good Samaritan goal - they value seeing someone serve in the Good Samaritan
role. And by 18 months of age toddlers acquire the rudiments of perspective-taking and perform altruistic acts themselves, with happiness being a consequence but not a self-interested primary aim of their altruism. Rifkin (Ch. 3) also draws upon the neuroscience research of the past twenty-five years that demonstrates that ou brains are designed, predisposed from birth, to experience another's emotions as if they are our own in order to create bonds of sociality and caring. Humans with normal brains come pre-wired for empathy, activate depends upon nurture and not nature alone. While this empathic capacity is part of our natural endowment, we need to exercise and cultivate this capacity if we are to develop it rather tha having it overridden: "We are both a cooperative and competitive animal. But it is the former sensitivity that is wired to our biology and sets the ground rules. We are, first and foremost, a social species. Within that context we sometimes compete to advance our interests.
If, however, our self-interest strays too far from the social bond, we If, however, our self-interest strays
risk ostracization" (Rifkin, p. 129).

Especially in the second half of the twentieth century, notes Rifkin (p. 37), "We extended empathy to large numbers of human beings previously considered to be less than human, including women, homosexuals, the disabled, people of color, and ethnic and religious minorities, and encoded our sensitivity in the form of social rights of a more widespread level-jump in empathic expansion one in which our empathy will be inclusive of the entire biosphere in which we exist: "Climate change is forcing us to recognize our shared humanity and common plight; we are entering a new phase" (p. 615). We need biosphere consciousness, an empathic embrace of the 40-mile ban that encircles the planet and keeps us all alive, and an empathic
embrace of our fellow human beings within our biosphere, for "To be embrace or our fellow hir truly human is to be universally empathic ..." (p. 177)

Rifkin argues that the concentration of methane, carbon dioxide, and nitrous oxide in the atmosphere exceeds by far the natural range and natural gases, and this has prevented heat from exiting the plane and the trapping of gases within our biosphere. Resulting hurricanes, floods, droughts, wildfires, and rising and falling temperatures are already spawning tension, discord, conflict, displacement, and huma need. This environmental destabilization increases the importance other human beings around the planet and toward our natura other human beings around the planet and toward our natura
environment. We would do well to reverse the narcissistic trend which have distracted our attention during the past half century and discover transcendent purpose. Rifkin (p. 598) observes that "globa communications without any real transcendent purpose result in

Int J Journalism Mass Comm
ISSN: 2349-2635

In Rifkin's portrayal, for the first time in human history we are within potential reach of identifying the human race as our extended a collision course with entropic forces that we have set in motion. The task is upon us now, as Rifkin sees it and as the clock ticks, is to ever more swiftly and fully rise to our role as "homo empathicus.

\section{Electronic Colonialism: The Non-Empathic Empire?}

If global empathic consciousness expansion is indeed a need (and fit into this picture, into the meeting of this need for an enlargement of empathic concern to include the planet and our human family? In this section we will briefly attempt to advance the claim that media images and messages are disseminated to the world, remains contrarian to the development of global empathic consciousness. We will specifically and briefly focus upon two such media impediments: the pervasiveness of media violence with its antisocial (rather than odification and

\section{Electronic colonialism}

Elecronic colonialism theory, as discussed by McPhail [3], traces four principal periods of empire building: (1) military colonialism (e.g., the Roman Empire, BC to 1000 A.D.); (2) Christian colonialism (e.g.g., the Crusades, 1000 to 1600 ); (3) mercantlle colonialism (e.g., the the Caribbean, and the Americas). and most recently (4) electronic colonialism (1950 to the present). McPhail notes that electronic colonialism theory "deals with what happens to individuals when they are repeatedly exposed to foreign-produced communications. These messages convey foreign personalities, foreign history, foreign norms, foreign values, and foreign tastes. Frequently these values are t variance with indigenous cultures and lifestyles ... the goal of global coldes of large market share and maximize profits"

American-owned media corporations are consistently among the world's top global media empires, including Comcast, Disney, TimeWarner, Twenty-First Century Fox, Viacom, Google, Apple, Microsoft, and Facebook. Of the wo [4]. The U.S.A. is a the global media enterprise.

In the area of film, for example, one Hollywood film typically costs more to produce than the entire annual film budget of most other countries; nine of the top grossing films in the world have been
American; $80 \%$ of European box office receipts are from American films, and the majority of imported television programs are American; entertainment is Americas second-largest export to the world (for five of the past six years, after aerospace and military materials). In short, around the world And what is it that is repeatedly shown and sizes screens? We will focus here upon one of the global media staples: screen violence.

IJJMC, an open access journa
Volume 3. 2016.116

Citation: Gordon RD (2016) Global Empathic Consciousness Development: Mass Communication Hope? Int Journalism Mass Comm 3: 116. doi http://dx. doi. org/10.15344/2349-2635/2016/116

Page 3 of 9

Screen violence

Bushman et al. [5] recently examined the thirty top-grossing U.S. hat in the past twenty for viewers thirteen years of age and older) has gone up by more than $300 \%$. This is a dramatic rise, especially since violent imagery at the low-end of this distribution was already considered high in its time [6]. In fact, the current PG-13 level of violence is now even above the level of violence shown in current R-rated (adult) films. A full 94\% of the top-grossing PG-13 films since 1985 contain gun violence, and
PG-13 films accounted for more than half of all film revenue (and G-13 flys a which means that most children under thirteen watch PG-13 films not expressly designed for young children). These content analysis findings support and exceed previous findings on the prevalence of violence in American film and television [7], and show not only no decrease but a dramatic increase in the presence of violent imagery in film. And since 1994 the majority of revenues for the America film industry have not come from domestic release in America, bu believed in the film industry. travel well globally. Since the dialogre in action-oriented films with violence is secondary little is required or lost in language translation, and these visully-mediated narratives are readily understood around the world.

Effects research. But does violent imagery serve well the development of global empathic consciousness development? There have by now been more than fifteen $(N=15)$ separate meta-analyses

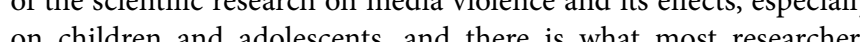
consider "strong evidence" that media violence is a causal risk factor for increasing aggressive cognition, aggressive affect, and aggressive behavior, and there is also recent direct evidence that media violence can significantly decrease empathic and prosocial behaviors 12]. This evidence has been obtained using multiple study design including gold-standard randomized experiments, cross-sectiona correlational studies, and longitudinal studies. Investigations have now been conducted in countries arond the world, and the patter skeptics $[13,14]$

Virtually every U.S. social scientific and health organization has gone on record as warning that screen violence has been convincingly demonstrated, through extensive scientific research, to contribst to aggressive attitudes, values, and behaviors. These organizations of record include the American Psychological Association, the American the National Academy of Science the Nationl Science Foundato the Centers for Disease Control and Prevention, the America Academy of Child and Adolescent Psychiatry, the American Medical Association, the American Academy of Pediatrics, the Academy of Family Physicians, and the Society for the Study of Social Issues and Public Policy.

\section{Interpretation of effects}

To help in conceptualizing the significance of media violence Violence [15] exposure to media violence at ages 6 to 11 is about as equally predictive of later youth violence as low $\mathrm{IQ}$, broken home
neglect, abusive parents, poor relations with parents, poor schoo

Int J Journalism Mass Comm
ISSN: $2349-2635$ performance, antisocial behaviors, psychological condition, weak social ties, or hyperactivity. Media violence is considered a risk actor for serious subsequent aggression, and becomes especially problematic when other nisk factors are also present. A 10-year old more likely to be seriously aggressive at age 18 as a child exposed to a single risk factor. Risk factors are interactive and multiplicative, and violent media imagery is one risk factor in the mixture. To use Potter's 16] analogy, neither fuel nor heat nor oxygen alone make fire, but the combination of this set of three factors can. Another way to clarify the meaning of a media aggression effect is to note that the statistical fffect size for the relationship between media violence and aggression is greater than the effect size of exposure to second-hand smoke

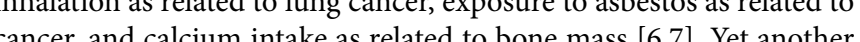
angle on the meaning of an aggression effect is offered by Hearold's 17] pioneering meta-analysis of 225 research investigations, and her conclusion that a single brief exposure (fifteen minutes or less) to media violence will increase a young persons aggression ranking by fifteen percentile points in an aggression distribution if the child or adolescent was initially angry prior to the violent imagery being consumed. For a non-angered child viewer, a single brief exposure resulted in a ten percentile point rise on an aggression distribution.
This is somewhat dramatic considering the single short-duration exposure. In life outside the laboratory it is the cumulative effect of media violence exposure from a range of mediated sources across lime that becomes of even greater concern. And also of importance, beyond imitative aggression effects, are fear effects (including the mean world syndrome), desensitization effects, excitation transfer effects, long-term cultivation effects, agenda-setting effects, priming effects, and contagion effects, all of which have been documented [18].

\section{Larger mental health context}

Combined with the demonstrated pervasiveness and power of media violence is the borderline mental health condition of much of the worlds population. According to the World Health Organization 19. planet approximately 450 million people suffer from mental health issues, and two-thirds of these persons will never seek or receive violence around the world combined with the prevalence of mental unhealthiness seems a volatile mixture, and counter-conducive to the building of empathic consciousness. Perhaps related to this, based upon a database analysis of over 5,000 terrorist incidents between 1968 and 1986 it was found that within two months after American network television coverage of international terrorist events there will is no initial television network coverage, $\mathrm{n}=26 \mathrm{vs.} \mathrm{n}=12$ [20].

\section{Youth vulnerability}

But even for adolescents and young adults not in need of treatment for mental health conditions, the transitional years are challenging developmentally, a time of confusion as to self-identity, uncertainty about the future, hormonal surges, mood changes, heightened
sensitivity and stress reactions, personal experimentation, tendencies to want to confront authority and the status quo, drug consumption, and all the rest. When media violence comes into this life-space with its "lessons" about how to handle frustration, how to express anger,
how to "get even" with people who get in your way or do bad things IJ/MC, an open access journa
Volume 3. 2016.116 
Citation: Gordon RD (2016) Global Empathic Consciousness Development: Mass Communication Hope? Int J Journalism Mass Comm 3: 116. doi: http://dx.doi.
org/10.15344/2349-2635/2016/116

to you, or how to treat strangers of other races and places and
ethnicities and religions ("out-group others"), then receptive minds ethnicities and religions ("out-group others"), then receptive minds especially among young males, are primed for modeled "solutions"
[22]. This can be an explosive intersection: graphic media portrayals [22]. This can be an explosive intersection: graphic media portrayal
of aggressive acting-out behaviors, and young male receivers in state of acute vulnerability. The human brain is the longest-maturing among mammals, not fully formed until the mid-to-late twenties, and at-risk for susceptibility to compelling and violent media imagery. Of particular import is the most recent line of neuroscience research in media aggression effects examining impacts of violent imagery upon the anesthesia" [23]

Issue of scale

Added to this is the "issue of scale" [22]. Let us imagine for the moment that there is no international mental health issue, and that adolescence and young adulthood are not particularly susceptible and vulnerable stages of life. Even so, if a given violent film or other mass medium stimulus had absolutely zero aggression effect on $99.9 \%$ o its world audience (unlikely, but for this issue of scale example this will be posited), for a total viewing audience of $100,000,000$ receivers
this would still mean that approximately 100,000 consumers of the violence imagery would still be adversely affected. The population the planet is now so large and the media violence so ever-present, that even in a 99.9\% "no effect" scenario there nevertheless remains sizable pool of impacted receivers who can potentially exert adverse impacts on their surrounding environments. This is especially true if we consider not only immediate dircet imitative effects, but delayed, cumulative, and indirect effects [24].

\section{Implications}

The violent and aggressive imagery that the world, and especially its young, are being led to consume is often at odds with the empathic
consciousness development that the world requires. Instead of fostering empathy and compassion, aggressive media imager increases hostile expectations and fears, increases aggressive emotions
and cognitions and actions, and decreases sympathy and real-world helping behaviors [25,26]. The opposite of what Rifkin [2] is hoping

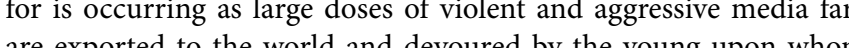
tomorrow most depends.

Yet there is always cause for communication hope, and there always need be. As Guare [27] put it, "It's amazing how a little bit of tomorrow can make up for a whole lot of yesterday." For example, in a recent study of thousands of uploaded You Tube videos collected during a three-month period during 2009 [28], only $13 \%$ of the sample conthed violence (often captures of video games), compare also more of an anti-violence message surrounding these depiction on You Tube than is the case on television. These early findings are encouraging. But ongoing research is needed, especially since each week the equivalent of 180,000 full-length movies (in terms of sheer visual footage) is being uploaded to You Tube [29].

Level of media violence is theoretically the most modifiable of the major contributing aggression factors. Poverty is difficult modifications in the quantity of graphic media violence are more

amenable to intervention. The relative modifiability of the gratuitous less violent world, and a more globally empathic, harmonious, and survivable tomorro

Let us briefly consider one additional media-related impediment (among of course others) to the development of global empathic among of cou
consciousness.

\section{Commodification and entertainmentization of consciousness}

Another counterforce to the development of empathic consciousness and biosphere awareness is the commercialization of consciousness. colonialism, advertising has a greater role and impact in foreigners' lives, values, and ultimately purchasing behaviors than the audio or video programming or print copy these ads surround" A closely related counterforce is the entertainmentization of consciousness. We will briefly allude to both, for these, along with violent and aggressive media content, can take us away from the vision hoped for by Rifkin. Instead, if they remain unchecked, these tendencies will perhaps ad earlier tried to affect.

The commercialization of human consciousness [30] is now at an all-time high in America and around the world, and poses anerous threats to well-being at personal, social, cultural, and

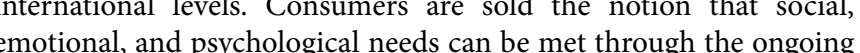
consumption of material goods. Ads seek symbolic control of their viewers' consciousness, linking products with something beyond the product that is attainable through the purchase of the product. often camouflaged via product placements, sponsolace-based ads, promotions, infomercials, logos, visual embeds, place based ads, commerce, life organized around material consumption. Highly skilled strategic compliance professionals endlessly seek new formats for thiggering automatic emotional responses within us, their target audiences to dvertisers.

This has resulted in personal, social, cultural, and environmental repercussions. In India, for example, commercial television exploded one governmentally-cot the urban centers in the country went form of satellite and cable-delivered commercial channels, about sixty in Delhi. Until that happened, Unnikrishnan \& Bajpai [31] observed different agenda - certainly television formed no part of it" ut ut their ater interviews with hundreds of Delhi children told a diferent story "Our study revealed consumerism is the new religion of the day and its most devout followers are children." These Indian researchers were concerned about the vast majority of the child audience who could in no way aftord what they saw advertised, and who therefore feel they from affluent families who "might feel convinced that only his class of from affluent familes who "inght feel convinced that only his class of Indians really count ... Since the ideology of consumption turns the burden and responsibility of caring about the rights and development of others in society" (p. 348).
Page 4 of 9 Citation: Gordon RD (2016) Global Empathic Consciousness Development: Mass Communication Hope? Int J Journalism Mass Comm 3: 116. doi: http://dx.doi.
org/10.15344/2349-2635/2016/116

Page 5 of 9

Ewen \& Ewen [30] worried decades ago about the ultimate new choice being offered is the implicit invitation to dispose of new choice being offered is the implicit invitation to dispose of
yesterday's choices. At the heart of this perpetual cycle is a market yesterday's choices. At the heart of this perpetual cycle is a market economy whose health depends upon the growing infirmity of the plane." An Ame hescarces of the plonet than a child growing gight times more of the resources of the planet than a child growing up in rura
India. Rampant consumerism keeps us perpetually out of touch with 政 al. [32] warned nearly twenty years ago that "We face an ecological and social crisis of major proportions, a crisis for which individualis market culture has not prepared its inhabitants."

Research suggests that for the past three decades or so narcissism a preoccupation with self, has gone up significantly in the West, an the world [33-35]. This accentuation of the self, concern with the self, adornment of the self, presentation of the sel/, concern with the pleasure and happiness of the self, concern with the (a) empathic consciousness that our biosphere and its people require. As Literacy and the Triumph of Spectecle "We have a right in the End of the self, to get whatever we desire. We can do anything, even belittle and destroy those around us, including our friends, to make money, to be happy, and to become famous." Focus narrows, and ethics and responsibility to anyone but self becomes elusive.

Related to the commodification of consciousness is the entertainmentization of consciousness. Postman [37] in his classic
work Amusing Ourselves to Death: Public Discourse in the Age of Show Business was among the first eloquent spokespersons to call ou attention to the fact that not only are the mass media entertainmentdriven, but as a resull, entertainment has becone the dominant forma for the representation of all experience in society. Entertainment is the supra-ideology by which all institutions are to be judged. As Postman pave been transformed into congenial adjunct of show burise largely without protest or even much popular notice. The result is the we are a people on the verge of amusing ourselves to death" Postman in the tradition of media theorists such as Innis and McLuhan, argued that "the bias of a medium sits heavy, felt but unseen, over a culture" As a result of the entertainmentization of everything, our attentio spans shrink even further, our literacy declines, our standards erode, our concern about serions isstes dwinles. As Hedges [36] has summarized it, "In an age of images and entertainment, in an age
of instant emotional gratification, we neither seek nor want honesty or reality. Reality is complicated. Reality is boring" Hedges offer these figures: more than $40 \%$ of college graduates will never read a single book in 2007; nearly a third of the population is illiterate or barely literate. A world in which commodification and incessant entertainment and spectacle and narcissism prevail in peoples
consciousness renders its inhabitants ill-prepared for surviving the consciousness renders
difficult times ahead.

While there are certainly other media-related issues beyond media violence and the commodification and entertainmentization of consclousness that deserve attention as well [38-42]), these are beyond the scope of this commentary.

\section{Mass Communication Hope?} IJJMC, an open access journa
Volume 3. 2016. 116

to make contribution, what is needed? Below eight possibilities are highlighted. As Jarecki [43] expresses it, "America is a work in progress, nade beter by the tough love of those who care for her." as we vew her wass bonming

So what can we academics do?

We can promote dialogue on ethical / neuroethical issues

A renewed world dialogue on the ethics of violence depiction, and increasingly from a neuroethics standpoint, is needed. Iacoboni [44], media violence from a neurophysiologic perspective: "Our instinct for empathy is part of the good news stemming from mirror neurons. Imitative violence could well be the bad news ..." He writes (Ch. 8) that mirror neurons produce automatic imitations that are nonconscious and that constrain our free-will: "The neural properties behavior especially simple acts of violence just as they car voptent as we have seen, the mirroring of smiling, foot shaking can explain, and so on." He observes that violence viewing stimulates arousal in the organism, and this arousal can reduce the inhibitory activity of super mirror neurons, and there is "uncontrolled biological automaticity that may undermine the classical view of autonomous decision making that is at the basis of free will." This leads to neuroethical issues that, lacoboni advises, need to be delliberated. lacoboni (p. 272) concludes his book with a call: "We have evolved to connect deeply bring us even closer to one another"

Is it neuroethical in today's world consciousness system to further saturate that system with mediated images of gratuitous violence? Is this necessary and appropriate? When is violent media imagery a ther in need of wigh the costs to humanity? These and other issues are help to arrange and suppont world inquiry in this ethical reanics

\section{We can further question underlying media assumptions}

The assumptions that "violence sells" and that the media are only respond media research, and it is not at all clear that violence itself is the crucial variable in increasing audience size [14]. Studies of the key be engaged to willingly watch a mediated stimulus that lacks violent imagery as the hook? For example, Blanchard et al. [45] found that people found the Russian roulette scene in The Deer Hunter to be their least enjoyable scene in the film, yet thirty-one real-life Russian roulette incidents across a four-year period were associated with that scene. Would audiences still be drawn to ultra-violent films even if the violent imagery were toned down by $25 \%$ to $75 \%$ ? And what might be compelling enough narratively and visually to gain audience possibly stimulating prosocial outcomes? How can the traditional element of dramatic "conflict" be constructively utilized in the pursuit of prosocial themes and effects? And what other foundational media industry assumptions need to be called into question, debated, and investigated? We academics have something to offer to this line of inquiry, examining foundational media assumptions.

What can communication scholars and researchers do next? Where

Int J Journalism Mass Comn
ISSN: $2349-2635$

IJMC an op 
Citation: Gordon RD (2016) Global Empathic Consciousness Development: Mass Communication Hope? Int J Journalism Mass Comm 3: 116. doi: http://dx.doi.
org/10.15344/2349-2635/2016/116

Page 6 of 9

\section{We can accelerate the call for media reform}

Concurrent with formal academic investigation, scholarly appeals to the media industries, producers, directors, writers, and actors is also the importance of greater ethical regard and responsibility as we continue into the 21 st century. Academic leadership would be helpful to social activism calling for media attention to biospheric concern and global empathic consciousness development.

How can pressure be strategically and systematically applied to promote media reform? How do citizens of the world who recognize the acuity of planetary conditions and events exert influence on the
media to be more of the solution and less of the problem? Media consciousness-raising, advocacy, and leadership efforts by mas communication scholars are needed, aside from the pursuit of yet further research [16]. The world cannot wait until all of the research knowledge and promote career advancement [35] but these priotites can no longer predominate. Considering the state of the world, this is an now rendered an anachronism. Energetic academic advisement, support, and leadership are vital to media literacy and reform efforts.

We can catalogue, comment upon, and publicize prosocial themes,

Peterson \& Seligman [46] found that virtues ubiquitous around the world include kindness, gratitude, forgiveness, hope, wisdom, self-restraint, authenticity, persistence, wisdom, open-mindedness a a other "higher" areas of human functioning is needed. Knowing where to turn for existing prosocial depictions, themes, and images would be of value to educators, other helping professionals, and prosocia societal change-agents, as would guidance in implementing the use of these media artifacts within educational curricula and media literacy efforts. Often embedded within violent narratives are prosocia elements that can be identified, extracted, commented upon, and made avaliable for wider dissenination. Such materials could be organized, indexed, and publized to a greater extent han is curnenly the case compensting for attention biss to the violent and agressive.

\section{We can further pursue prosocial media researc}

The prosocial side of the media research enterprise has commanded far less research attention than has the media violence side of the
equation. The research that does exist tends to document the positive benefits of constructive media portrayals of prosocial behaviors acros multiple forms of media including video games, music, television radio, and film [13,48-52,]. The modeling of virtuous human action and the cultivation of perspective-taking and empathy via the media fits within a general learning model that incorporates concepts and principles from social learning theory, script theory, cognitive an neo-association theory, cultivation theory,
social information processing theory [53]

Prosocial beliefs, attitudes, affects, and behavioral scripts are susceptible to modiftation by sliffully designed media interventions. Prosocial media depictions of cooperation, generosity, tolerance compassion, helping, hope, wisdom, forgiveness, etc., can be eve

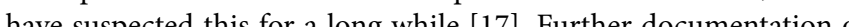
prosocial effects and the specification of the precise mechanisms by

which they work is perhaps, at this stage, more important than further media violence research. We have worked extensively to chronicle the darker side of media effects across the decades, and now the time is auspicious for researching the brighter side of human capacity.

For example, in a recent study of prosocial media effects [48], samples of 200 to 500 participants (mean age of 21) were studied in uuthors report this totia, Germany, Japan, Romania, and the U.S. The relationship between prosocial media use, empathy, and real-world helping behavior across a range of cultures. The main finding, using media group strat equation model, was that the entertainment empathic concern and perspective-taking and this medites selfreported helping behavior over time in the real-world, and with no major gender, age, or even cultural differences: "These findings underscore the fact that media are powerful teachers. Just as exposure to violent media can lead to negative outcomes such as desensitization and increased aggression, use of prosocial media can lead to positive changes such as increased empathy and helping" [48]. Another recent Burundi Afocat [4]. The reserchers found tha intervention in group trust, social distance in-group superiority and responsibility attributions were all affected in a constructive direction for receivers of a radio drama across time, compared to non-listeners. They view this finding as consistent with the previous limited research in the area, though most of the previous studies of media impact in prejudicereduction interventions have used single-exposure media programs.

Ongoing investigations of the effects of portrayals and discourses electronic media and their applications, as is advisory assis
helping these prosocial messages to more regularly go viral.

\section{We can link to positive psychology research efforts}

Parallel to the recent interest in pursuing prosocial media effects research, "positive psychology," a term coined by Abraham Maslow [54], has blossomed in the past two decades [55]. Much of the research (rather than the "darker") side of hulogy in investigating the "lighter" seem auspicious for stimulating a surge in innovative prosocil media effects research. Positive psychology topics have included forgiveness, gratitude, awe, joy, happiness, love, humanity, kindness, compassion, transcendence, hope, spirituality, and others [56]. Seligman and colleagues summarize the science of positive psychology as the study of positive emotions, virtues, and strengths of character that enabling institutions [46]. Positive psychology aims to identify the character requiements necessry for a vible and heolthy society. Attention to documenting the positive effects of prosocial media themes and content dovetails with this burgeoning applied scientific positive psychology movement. Making the link between prosocial media effects research and positive psychology more explicit could be useful at theoretical and practical levels.

We can synthesize diverse stands of prosocial research across disciplinary lines

What have we learned from previous research in mass communication, social psychology, the neurosciences, personality
research, sociology, social epidemiology, and other inquiry from Citation: Gordon RD (2016) Global Empathic Consciousness Development: Mass Communication Hope? Int Journalism Mass Comm 3: 116. doi: http://dx.doi.
org/10.15344/2349-2635/2016/116

Page 7 of 9

disciplines far and wide that will allow us to better predict how to inspire a shared vision of greater worldwide human cooperation and environmental respect? And if the people of the planet are fated to
continue consuming large mediated doses of violent and aggressive continue consuming large mediated doses of violent and aggressive imagery with themes of attack, defense, and revenge, what can be
done after consumption to help mitigate these effects? Synthesizin previous research broadly related to these questions is a worthwhile scholarly pursuit. We often know more than we realize we know, and those who can cull, distill, and integrate far-flung knowledge perform extremely valuable service.
these whe can cull,

We can stimulate and facilitate ongoing dialogue on what is needed

Of value is continuing active dialogue among mass communication scholars on the question itself, "What is needed?" Especially if we assume that we cannot entirely rely on media producers to decrease the export of violent and aggressive media imagery, at least in the near-term, then what courses of action and research can be pursued that accommodate to this, yet that can assist in buffering impact? To reflect aloud in community, generating widespread and free-flowing a healthy pursuit: where to go from here? Hearings befort would be a healthy pursuit: where to go from here? Hearings before Congress,
statements from professional associations, endless violence effects research, all of this can appear to be for naught. So what other options are there? What is possible that has not already been done? Where are the leverage points for change? Open and generative exploratory discourses are needed among mass communication scholars and within public arenas.

\section{Conclusion}

Our scholarly responsibility to the planet

Ethics in the behavioral sciences have often been discussed in terms of the ethics of the collection and analysis of data and the treatment of research participants. Far less attention, especially within communication studies, has been paid to the ethics of our responsibility to society, how our roles as scholars relate to our
larger responsibilities as citizens of our planet Earth [57-59]. Yet as Skolimowski [60] warned long ago, "Knowledge which does no aid the species in the process of overall survival and which does not as Houston [61] advised, "It is time to educate ourselves to the web of kinship and fellow-feeling necessary on this endangered planet -- to awaken all those dor his role as conqueror of nature and other people. We are challenged, as never before, to achieve a new humanity and a new way of nurturing the species in harmony with nature and with each other. And, finally, the words of Stagner [62] from sixty years ago are truer today than that it is now possible for all men (sic) to die together. Relatively little is being done to make it possible for them to live together" The warnings have been with us for a long while.

Gazzaniga [63], in Human: The Science Behind What Makes Us Unique, concludes his volume with the thought that "the ablity to wish or imagine that we can be better is notable. No other species of the word of Geore Hebt been evolutionary changes that took place without ind hidul reaction. But moral changes are those that take place through the action of the individual as such. S/he becomes the instrument the means, of changing the old into a new order....by asking what is right, 列 inclusive option not in the original).

Of course there will be resistance to prosocial change efforts within the violence entertainment establishment, not only within the of, violent media imagery (mediated visually and/or aurally). In one recent study for instance [65] those most opposed to nonviolent prosocial interventions were those highest in aggression themselves. A "boomerang effect" is to be expected. But as Japanese communication scholar Satoshi Ishii [66] has urged, "It is now the further develop harmonious, peaceful and sustainable world ond not by means of mass-devastating militaristic or terroristic violence but through intercultural, interethnic, international interreligious and intercivilizational communication so that the $21^{\text {st }}$ century will not be the last century for the whole living world" (italics in original). As be social.

\section{Shades of Marshall McLuha}

McLuhan [67] presciently and famously observed more than fifty years ago that "Today, after more than a century of electric global embrace, abolishing both space and time as far as our planet is concerned." McLuhan wrote that any such extension of our central nervous system into the whole of mankind "affects the whole psychic and social complex. Anyone familiar with the preponderance of violence in media content, and the triune structure of the human brain, cannot help but wonder whether there has not been survival mechanisms) and the limbic brain system (including our "fight or flight" reactions) into the world community rather than an extension of the neo-mammalian brain functions that have evolved most recently. It is this most recent evolutionary development of the neo-mammalian brain that includes the higher-order human brain functions including thinking, reasoning, reflecting, emotional self-management, language, empathy, compassion, and other such systems exensions of the global Western medie central nervous drawing excessively from the lower and more primitive brain regions, and that it is time to upgrade our central nervous system extensions into the world consciousness system. Or, to at least counterbalance hem with other more constructive extensions and flows from higher regions. The aspiration of our time for wholeness, empathy wrote McL of awareness is a natural adjunct of electric technology ultimate harmony of all being." McLuhan is even more right norns the he was then: electronic interconnectivity, especially in the most recent twenty-year period, has brought to multitudes of young people across our globe this hunger for wholeness, empathy, depth of awareness, and harmony of all being. How to help bring these into greater presence amidst a torrent of images of visual harm and revenge, and how to get past narcissistic self-preoccupation and disengagement, remains the questin. As Mctuhan knew, there is a predictable "numbness that also knew, the electronic extensions of humankind need to eve as he be brought into "orderly service"
Int J Journalism Mass Comm
ISSN: 2349-2635
IJJMC, an open access journ 
As McChesney [29] has commented, communication technologies with unlimited potential have been usurped by the uses to which they have been put. In America it was the hope of early broadcast
enthusiasts in the 1920s and 30s, especially within the academy, that enthusiasts in the 1920s and 30s, especially within the academy, that
the electronic media would serve the public interest with conten from the arts and humanities that would lift the human spirit, and of power in society [38]. As critical media scholars are quick to poin out, this noble vision has not come to pass, as economic interests have instead reigned supreme.

Yet hope springs eternal, and hope we must have. It is not that mass communication hope is not worth having, but rather that such hope cannot be left entirely in the hands of the media monoliths. If we are to have mass communication hope, we will want to find
our way of contributing to consciousness-raising to to nudge constructive change forward. May those of us who have dedicated a major part of our lives to the study and practice of mass communication find ways to contribute to a lessening of numbness, and help meet human and planetary needs for wholeness, empathy depth of awareness, and harmony of all being. Our very survival as species might depend upon exactly th

\section{References}

Simonson D (1996) Dreams of democratic togetherness: Communication
hope from Cooley to Katz. Critical Studies in Mass Communication 13: 324

2. Rifkin $J$ (2009) The empathic civilization: The race to global consciousness

McPhail TL (2002) Global communication: Theories, stakeholders, and
trends. Boston, MA: Allyn \& Bacon. Le V (2015) The world's largest media companies of 2015

Le V (2015) The worl's's largest media companies of 2015 .
Bushman BJ, Jamieson PE, Witz

6. Rosenthal R (1986) Media violence, antisocial behavior, and the social
consequence of small effects. Journal of Social Issues 42: 141-154. Comstock G, Scharrer E (2007) Media and the American child. San Diego
Academic Press.

Anderson CA, Bushman BJ, Donnerstein E, Warburton W (2015) SPSS Anderson CA, Bushman BJ, Donnerstein
research summary on media violence. Society for the Psychological Study
of Social Issues 15: 4-19. Media violence commission of the International Society for Research on
Aggression: Report (2012) Aggressive Behavior 38: $335-341$.

Saleem M, Anderson CA, Gentile DA (2012) Effects of prosocial, neutral, Saleem M, Anderson CA, Gentile DA (2012) Effects of prosocial, neutral,
and violent vidoo games on children's helpful and hurtful behaviors. Aggr
Behav 38 : 281-287.

11. Anderson CA, Shibuya A, hori $\mathrm{N}, \mathrm{Swing} E \mathrm{EL}$, Bushman BJ, et al. (2010
Violetent video game effects on aggression, empothy and prosocicil behavior in Ealent video game eifects on aggression, empathy, and prosocial behavior
136: 151-173. Western countries: a meta-analytic review. Psychol Bull
int 2. Anderson CA, Dill KE (2000) Video games and aggressive thoughts,
feelings, and behaviors in the laboratory and in life. $J$ Pers Soc Psycho
$78: 772-790$.

13. Anderson CA, Gentilie DA, Buckley $\mathrm{KE}$ (2007) Violent video game effects
on children and adolesscents: Theory, research, and public policy. Oxford,
End

14. Potter WJ (2003) The 11 myths of media violence. Thousand Oaks, CA

15. United States Surgeon General's Office (2000) Youth violence: A report of
the surgeon general. Washington, D.C.: Printing Office of the United States

Potter WJ (2016) Media literacy, 8th ed. Thousand Oaks, CA: Sage

17. Hearold $S$ (1986) A synthesis of 1043 effects of television on social
behavior In $G$. Comstock (Ed) Public communication and behavior ( $(\mathrm{1}$. behavior. In G. Comstock (Ed)., Public communication and behavior (v.1,
6 5-133). New York: Academic Press. 18. Gordon RD (2007a) The Asian communication scholar for the 21st century.
China Media Research 3: 50-59.

19. World Health Organization (2001) World health report 2001: Mental illness.
Geneva, Switzerland: WHO.

20. Weimann G, Winn C (1994) The theater of terror: Mass media and

Strasburger VC (Ed.) (2012) Children, adolescents and the media. St.
Louis, MO: W.B. Saunders.

22. Berkowitz L (2000) Some effects of thoughts on anit- and prosocial influences of media events: A cognitive neoassociation analysis. In $\mathrm{S}$.
Prince (Ed)., Screening violence (pp. 205-236). New Brunswick, NJ:

23. Stockdale LA, Morrison RG, Kmiecik MJ, Garbarino J, Silton RL (2015) Emotionally anesthetized: media violence induces neural changes during
emotional face processing. Soc Cogn Affect Neurosci 10: 1373-1382.

24. Gordon RD (2002) The question of media violence in the USA. Human
Communication 5: 331-350.

25. Bushman BJ, Anderson DA (2002) Violent video games and hostile
expectations: A test of the general aggression model. Pers Soc Psychol Bull 28: 1679-1686.
B.

26. Prince $S(2000)$ Screening violence. New Brunswick, NJ: Rutgers
University Press.

of the body. New York, NY: Grove Press 28. Weaver A, Zelenkausekaite AJ, Samson $L(2012)$ The (non) violent world
of You Tube: Content analysis in web video. Journal of Communication 62 :
$10055-1083$.

29. McChesney R (2013) Digital discontent: How capitalism is turning the
internet against democracy. New York: New Press.

30. Ewen S, Ewen E (1992) Channels of desire: Mass images and the shaping
of American consciousness. Minneapolis, MN: University of Minnesota

31. Unnikrishnan N, Bajpai $S$ (1998) The impact of television advertising on
children. Thousand Oaks, CA: Sage.

32. Budd $\mathrm{M}$, Craig $\mathrm{S}$, Steinman $\mathrm{C}(1999)$ Consuming environments: Television
and commercial cuture. New Brunswick, NJ: Rutgers University Press.

33. Twenge JM, Foster JD (2010) Bith cohort increases in narcissistic personality tests among American college students, 1982-2009. Socia
Psychological and Personality Science 1: 96-106.

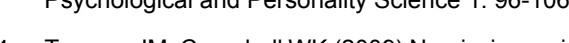

34. Twenge JM, Campbel WK (2009) Narcissismepict
entitlement. New York, NY: Simon and Schuster.

35. Derber $C(2000)$ The pursuit of attention: Power and ego in everyday life.

36. Hedges $C(2009)$ Empire of illusion: The end of literacy and the triumph of

37. Postman N (1985) Amusing ourselves to death: Public discourse in the age
of show business. New York: Penguin.

38. McChesney $R$ (1999) Rich media, poor media: Comm
dubious times. Urbana, L: University of llinois Press.

Mcchesney, R (2007) Communication Revolution: Critical junctures and the future of media. New York: New Press.

40. Bugeja $M(2005)$ The interpersonal divide: The search for community in a
technological age. New York, NY: Oxford University Press.

Alger D (1998) Megamedia: How giant corporations dominate mass media,
distort competition, and endanger democracy. New York, NY: Rowman \& Littlefield.

42. Mitroff III, Bennis W (1993) The unreality industry: The deliberate
manufacturing of falsehood and what it is doing to our lives. New York, NY:
Oxford University Oxford University Press.

43. Jarecki (2008) The American way of war: Guided missiles, misguided men,
and a republic in peril. New York: Free Press.

44. lacoboni $\mathrm{M}(2008)$ Mirroring people: The new science of how we connect
with others. New York: Farrar, Strauss and Giroux. Int J Journalism Mass Comm
IISSN: 2349-2635

IJJMC, an open access journal
Volume 3. 2016.116
Citation: Gordon RD (2016) Global Empathic Consciousness Development: Mass Communication Hope? Int J Journalism Mass Comm 3: 116. doi: http://dx.doi.
org/1015344/2349-2635/2016/116 45. Blanchard DC, Graczyk B, Blanchard RJ (1986) Differential reactions of
men and women to realism, physical damage, and emotionality in violent
films. Aggressive Behavior 12: 45-55.

46. Peterson C, Seligman MEP (2004) Character strengths and virtues: A
handbook and classification. Washington, D.C.:. American Psychological
Association.

47. Park N, Peterson C, Seligman MEP (2005) Character strengths in forty
nations and fifty states. Unpublished manuscript, University of Rhode

48. Prot S, Gentile DA, Anderson CA, Suzuki K, Swing E, et al. (2014) Longterm relations among prosocial-
behavior. Psychol Sci 25: $358-368$.

49. Bilali R, Vollhardt JR, Rarick JRD (2015) Assessing the impact of a media-

50. Greitemeyer $T$ (2011) Effects of media on social behavior: When and why
does media exposure affect helping and aggression? Current Directions in Psychological Science 20: 251-25.

51. Greitemeyer T, Osswald $S(2010)$ Prosocial video games reduce aggressive
cognitions. Journal of Experimental and Social Psychology 45: 896-900.

52. Greitemeyer T (2009) Effects of songs with prosocial lyrics on prosocial
behavior. Pers Soc Psychol Bull 35: 1500-1511.

53. Maier JA, Gentile DA (2012) Learning aggression through the media (Ed.), The psychology of entertainment media: Blurring the lines between
(E.then

54. Maslow AH (1954) Motivation and personality. New York, NY: Harper.

55. Seligman MEP, Steen TA, Park N, Peterson C (2005) Positive psychology
progress: Empirical validation of interventions. American Psychologist 60 progress: Empircal

56. Lopez SJ, Pedrotit IT, Snyder CR (2015) Positive psychology: The scientific
and practical explorations of human strengths, 3rd ed. Thousand Oaks, CA: Sage.

57. Gordon RD (2007b). Beyond the failures of Western communication theory.
Journal of Multicultural Discourses 2: 89-107.

58. Gordon RD (1988) Communication research and social responsibility
Speech Communication Annual 2: 23 -102.

. Gordon RD (1982) Research editorial: Practical theory. Spectra 18: 1-2.

60. Skolimowski H (1973) The twilight of physical descriptions. In I. Laszlo
(E.)., The world system: Models, norms, variations. New York, NY: George
Braziller.

Houston JM (1977) The mind of Margaret Mead. Quest 77: 22-25.

62. Stagner R (1956) The psychology of industrial conflict. New York, NY: Wiley
and Sons.

63. Gazzaniga MS (2008) Human: The science behind what makes us unique

New York: HarperCollins.

64. Mead GH (1934) Mind, self, and society (Ed., C. Morris). Chicago, III.
University of Chicago Press. Cardaba MAM, Brinol P, Brandle G, Ruiz SR (2016) The moderating role
of aggressiveness in response to campaigns and interventions promoting
antitiviolence attitudes. Aggr Behav.

66. Ishii S (2007) A Western contention for Asia-centered communication
scholarship paradigms: A commentary on Gordon's paper. Journal of scholarship paradigms: A comment
Multicultural Discourses 2: 108-114.

67. McLuhan M (1964) Understanding media: The extensions of man. New
York: MCGraw-Hill/Signet.

(20)
based intervention to prevent intergroup violence and promote positive
intergrouu relations in Burundi. Journal of Community and Applied Social
Psychology 26: 221-235. entertainment and persuasion, 2nd ed. (267-299). New York: Taylor
Francis.

Ver.

